\title{
The Responsible Research and Innovation (RRI) Maturity Model: Linking Theory and Practice
}

\author{
Bernd Carsten Stahl ${ }^{1, *}$, Michael Obach ${ }^{2}$, Emad Yaghmaei ${ }^{3,7}$, Veikko Ikonen ${ }^{4}$, Kate Chatfield ${ }^{5}$ \\ and Alexander Brem ${ }^{6,7}$ \\ 1 Centre for Computing and Social Responsibility, School of Computer Science and Informatics, \\ De Montfort University, The Gateway, LE1 9BH Leicester, UK \\ 2 Health Division at TECNALIA Research \& Innovation, Mikeletegi Pasealekua, 1-3, \\ 20009 Donostia-San Sebastián, Spain; michael.obach@tecnalia.com \\ 3 Department of Values, Technology, and Innovation (VTI), TU Delft, Jaffalaan 5, 2628 BX Delft, \\ The Netherlands; E.Yaghmaei@tudelft.nl \\ 4 Value-Driven Decision Making, VTT Technical Research Centre of Finland Ltd., Tekniikankatu 1, \\ 33720 Tampere, Finland; veikko.ikonen@vtt.fi \\ 5 School of Health Sciences, University of Central Lancashire, Fylde Rd, PR1 2HE Preston, UK; \\ KChatfield@uclan.ac.uk \\ 6 Chair of Technology Management, Friedrich-Alexander-Universität Erlangen-Nürnberg, Fürther Str. 246c , \\ 90429 Nürnberg, Germany; alexander.brem@fau.de \\ 7 Technology Entrepreneurship and Innovation (TEI), University of Southern Denmark, Alsion 2, \\ 6400 Sønderborg, Denmark \\ * Correspondence: bstahl@dmu.ac.uk; Tel.: +44-116-207-8252
}

Academic Editor: Marc A. Rosen

Received: 5 May 2017; Accepted: 10 June 2017; Published: 16 June 2017

\begin{abstract}
Responsible research and innovation (RRI) is an approach to research and innovation governance aiming to ensure that research purpose, process and outcomes are acceptable, sustainable and even desirable. In order to achieve this ambitious aim, RRI must be relevant to research and innovation in industry. In this paper, we discuss a way of understanding and representing RRI that resonates with private companies and lends itself to practical implementation and action. We propose the development of an RRI maturity model in the tradition of other well-established maturity models, linked with a corporate research and development $(R \& D)$ process. The foundations of this model lie in the discourse surrounding RRI and selected maturity models from other domains as well as the results of extensive empirical investigation. The model was tested in three industry environments and insights from these case studies show the model to be viable and useful in corporate innovation processes. With this approach, we aim to inspire further research and evaluation of the proposed maturity model as a tool for facilitating the integration of RRI in corporate management.
\end{abstract}

Keywords: responsible research and innovation; RRI; industry; maturity model; R\&D management; innovation process

\section{Introduction}

The discourse concerning responsible research and innovation (RRI) has reached a significant level of sophistication. Following initial attempts to define the term and promote it as a relevant aspect of research governance [1], there is now growing agreement on key aspects of RRI and possible means of implementation. This does not mean, however, that RRI is unproblematic. There are deep-seated contradictions and problems that can limit the potential success of RRI. One example is the desire of RRI to broaden the conversation about research and innovation (R\&I) to include wider stakeholder groups; this sits very uneasily with the traditionally tightly focused definition of excellence in research. 
Another challenge for RRI, and one that constitutes the basis of this paper, is that much of the discourse concerns publicly funded research. This is problematic because a significant amount of research, and a large proportion of innovation activities, are conducted by privately funded organisations. It is not immediately obvious whether the arguments in favour of RRI are relevant to companies, or whether the incentive structures that are being put in place resonate with companies' R\&I processes. Hence, there is a need for investigation of the relevance and the nature of RRI in industry.

This paper takes, as a starting point, the stance that RRI is relevant to companies and can have a positive impact on the performance of companies in different ways. For instance, the adoption of RRI could help a company develop its links with stakeholders including customers; it could facilitate alignment with societal and regulatory expectations and requirements; and it could improve employee satisfaction. These potential benefits hinge on the company's understanding of the content and implications of RRI and the subsequent realisation of its benefits, but this presents a challenge; companies and individuals who work in R\&I roles typically do not engage with the predominantly academic RRI discourse. It is, therefore, vital that the RRI discourse is translated in keeping with the environment and context of private company operations.

Once a company has accepted that RRI offers an interesting value proposition, the next step for the company will be to understand how, and to what degree, its existing practices reflect RRI. Companies, and the individuals that work for them, invariably carry existing responsibilities. Some of these responsibilities will align well with RRI, but others may not. It is important to find a way to describe RRI that will allow a company to reflect upon the potential alignment of its existing practices as well as to recognise what is needed for furthering RRI integration. In technology-oriented industries, RRI will be typically linked to the research and development activities of new and existing products.

At present, there is no structured way for a company to evaluate the degree to which its practices align with RRI. This paper proposes a model of RRI maturity that could be used for this purpose. The RRI maturity model is founded upon a recent and significant effort to investigate RRI in industry. This has included 30 semi-structured interviews with key industry personnel, five bottom-up case studies, a large-scale Delphi Study, 15 focus groups, and four in-depth case studies. The insights gained from these various activities highlighted a need for the synthesis of understanding of RRI in industry and fed into the development of the RRI maturity model.

Through the development of the maturity model, this study addresses a missing central concept in the RRI discourse and may facilitate the integration of the various disparate aspects that constitute RRI into a coherent whole. In addition to a theoretical contribution, the paper makes a crucially important practical contribution to RRI in industry. It offers a way forward for companies to engage with RRI and steers the processes and outcomes of their R\&I in sustainable, acceptable and desirable directions.

The paper begins with discussion of how the RRI discourse can be understood in a way that is relevant to industry. This section briefly reviews key aspects of RRI literature and explores potential motivations for industry to engage with RRI. Additionally, it unpacks the key components of RRI and ways to understand or measure them. The following section charts the path towards an RRI maturity model. Here, we provide an overview of the empirical research that underpins the paper and combine this with a theoretical understanding of RRI to define the dimensions of the RRI maturity model. The relevance of the RRI maturity model is shown using empirical research. The conclusion discusses ways of advancing the RRI maturity model and points to further research and subsequent activities aimed to disseminate RRI more broadly.

\section{Translating the RRI Discourse into Industry Contexts}

The concept of RRI can be understood as an attempt to promote a novel governance method for R\&I. It has been described as a "way of thinking more systematically about the public benefits of science and technology-based research" [2]. Various definitions from key contributors to the discourse are consistent with this broad description. For example, the most widely employed definition by von Schomberg [3], sees RRI as a: 
"transparent, interactive process by which societal actors and innovators become mutually responsive to each other with a view to the (ethical) acceptability, sustainability and societal desirability of the innovation process and its marketable products (in order to allow a proper embedding of scientific and technological advances in our society)".

This definition is also in accordance with the aforementioned broad description, as are most others [4-6]. Stilgoe et al. [7] proposed a framework for RRI that focuses on the four integrated dimensions of anticipation, reflexivity, inclusion and responsiveness. This was adapted and adopted by the UK Engineering and Physical Sciences Research Council to form the AREA (anticipation, reflection, engagement and action) framework [8]. Another highly influential contribution to the RRI discourse comes from the European Commission (EC) that, as the largest funder of research in Europe, has a significant influence on research policy. The EC has adopted RRI as a cross-cutting activity that informs all aspects of its Horizon 2020 research framework programme in years 2014 to 2020. In the EC's view, RRI consists of a number of pillars that correspond to established research policy areas: civil society engagement, gender equality, science education, open access, ethics compliance and governance $[9,10]$.

While the term 'RRI' has only been in use from around 2010, the concept is based upon a number of pre-existing concepts and traditions. These include technology assessment, applied ethics, science and technology studies and other ways of understanding and dealing with new developments in science and technology [11]. We suggest that a good way of understanding the novelty of RRI, and to tease out its practical relevance, is to understand the concept as a higher level or meta-responsibility [12]. When understood as a meta-responsibility, the role of RRI is to shape, maintain, develop, coordinate and align existing and novel R\&I-related processes, actors and responsibilities, with a view to ensuring desirable and acceptable research outcomes.

The value of this interpretation becomes obvious when one looks at R\&I environments and practices. These environments, like all social environments, are characterised by a multiplicity of pre-existing responsibilities that may be mutually enforcing but may also be contradictory. The individual researcher's responsibility for validity of data and analysis sits alongside their personal responsibility as a parent and their citizen's responsibility for public welfare. The research group and institution has responsibilities, for example, for providing a supportive environment and upholding regulations, and there are other actors, such as research funders or policymakers, who have responsibilities for the overall research system and distribution of resources. This is a complex and dynamic mix in which there are numerous, potentially conflicting aims and trajectories. If the aim of RRI is to enhance research governance for ensuring acceptability, desirability and sustainability of research processes, outcomes and purposes, then it needs to be in a position to perceive and affect all of these in equal measure. As such, RRI must sit at a higher level, on the meta-level, thus turning it into a meta-responsibility.

This view of RRI as a meta-responsibility is crucial for the development of the RRI maturity model. Before we can start to develop this model, however, it is important to understand the relevance and implications for RRI in industry.

\subsection{Motivations for RRI in Industry}

The above discussion of RRI is applicable to any environment that undertakes R\&I. However, in practice, it has emerged, predominantly, in the arena of publicly funded research. The most notable examples of implementation currently lie with public research funders such as the EC, or national research funders like the UK EPSRC, the Dutch NWO or the Norwegian Research Council.

This focus on publicly funded research is problematic for the uptake of RRI because a large proportion of research and the majority of innovation that is close to the market is undertaken by private companies. If RRI is to be relevant for the entire R\&I ecosystem, then it must be relevant for industry as well. This poses problems because there are obstacles to the adoption of RRI by private companies. These obstacles are discussed in more detail in other papers in this special issue see, e.g., [13] but one basic challenge, given that the term has emerged from a discourse of policy 
concerning publicly funded R\&I, is that RRI remains largely unfamiliar to companies. Even more of a challenge, is the question why a company would engage with RRI in the first place. This question is discussed by other scholars interested in RRI in industry [14,15], but in summary, the primary motivations for the adoption of RRI include the following three points.

1. RRI can contribute to the success of the organisation, for example, through improved corporate image, by strengthening ties with customers or by improving employee wellbeing.

2. RRI can be viewed as an integral aspect of other existing organisational commitments, notably as an extension of the organisation's work on corporate social responsibility [16].

3. RRI can be of specific relevance in particular industries, for example, in the case of ICT for health, demographic change and wellbeing, where numerous innovation processes can be highly regulated and align closely with the values of RRI.

This paper does not explore these matters in any more detail. However, a premise of our maturity model development is that RRI can be of value to organisations and that it can be perceived as such. Our approach suggests that organisations would benefit from an understanding of how their current practices map onto RRI and how this relates to their environment and competitors. For such an understanding to develop, it is first necessary to clarify the constituents of industry and RRI. For this, we refer our discussion on the following understanding of industry, based on the Merriam Webster dictionary:
"a department or branch of a craft, art, business, or manufacture; especially: one that employs a large personnel and capital especially in manufacturing (https:/ / www.merriam- webster.com/dictionary/industry)".

Hence, industry as a term is in our understanding a collective term for companies of a certain size, which usually produce something. We are not explicitly talking about small- and medium-sized enterprises or start-ups; this offers room for interesting future research. These types of companies have very different characteristics compared to larger and more established firms [17], which is reflected especially in their resource situation. So, it can be assumed that the way in which RRI is treated in such firms is different.

\subsection{Components of $R R I$}

The intention of RRI to steer R\&I activities in ways that render them acceptable, desirable and aligned with social preferences can be broken down into a number of aspects and components. One possible way of structuring this is to consider the 'three Ps' of R\&I: the purpose, process and product. This view of RRI is derived from the AREA-plus framework that was developed by Jirotka et al. [18] in an attempt to render the rather generic AREA framework more accessible and provide specific guidance for the field of ICT. Each of these aspects can significantly affect the desirability and acceptance of a company's R\&I activities.

Purpose refers to the reason(s) why R\&I is undertaken. In companies, this may be self-evident, namely, as a way of improving their products or services and strengthening their market position. It is important, however, to acknowledge that the purpose of research can have serious repercussions. A prominent example of this, from the publicly funded arena, was the SPICE (Stratospheric Particle Injection for Climate Engineering) project [19]. This geoengineering project aimed to develop a prototype of a technology that could inject sulphur particles into the stratosphere to counter global warming. The actual prototype itself did not raise any environmental or other significant concerns, but the concept of geo-engineering itself proved to be highly contentious. The project experienced a public backlash based on fundamental opposition to the purpose or idea behind the project, namely, that we should use geoengineering technologies to deal with global warming.

There are numerous examples from the private sector that indicate the importance of the purpose of R\&I. Many of these come from contentious fields such as nuclear power, chemical or nanotechnology 
industries. One well-known example concerns the use of genetically modified organisms in the form of the so-called "terminator seed" produced by Monsanto. Many viewed this development as an attempt by a large agrotechnical company to force farmers to become dependent upon a private company for purchase of their seeds. The introduction of sterile crops would prevent farmers from producing their own seed supplies. This case raised a number of ethical issues [20] as well as concerns about intellectual property rights and other questions [21]. The narrative is controversial and contested (http:/ / www.monsanto.com/newsviews/pages/terminator-seeds.aspx, accessed on 16 March 2017), but the intention here is not to pass judgement. The important lesson for RRI is that because the purpose of the innovation was viewed purely as a means of increasing profits for the company, which delegitimised any potential benefits. Public discourse is often critical of companies that are believed to prioritise monetary interests over and above the interests of their consumers, thereby creating an obvious tension for companies whose survival depends upon economic profit. The impact of the perceived purpose of R\&I should not be underestimated, even though the literature focuses in much more detail on the next two components, process and product.

Process refers to all of the activities that are undertaken in the pursuit of R\&I. A key tenet of the academically oriented RRI discourse is that modification of R\&I processes may be necessary to align them with RRI principles and values. The work by Stilgoe et al. [7], as adopted by the UK EPSRC's AREA [8] framework, falls under the heading of process. Here, the concepts of anticipation, reflection, engagement and action suggest processes that should be incorporated into R\&I endeavours.

One further component of the process dimension of RRI is that of research ethics. Research ethics was first developed as a coherent set of principles and actions following the Second World War [22], notably in relation to biomedical research. Its primary aim was to protect research participants from harm. Nowadays, research ethics processes are found across disciplines and broadly cover most areas of research that involve humans or animals. The European Commission takes a broad view of the term, including issues such as animal protection, prevention of misuse or dual use [23]. While the extension of research ethics beyond its original remit to protect research participants is not welcomed by all $[24,25]$, it is important to note that ethics is increasingly seen as a part of R\&I processes.

Product, here, is used to refer to the outcomes of R\&I. The outcomes of R\&I will include a variety of factors but for effective RRI, these must lead to certain identifiable consequences. We suggest that most of the RRI pillars that the European Commission [10] has proposed fall into this category. For example, the tangible impact of RRI may be visible through greater equality of gender (or other characteristics), through openness of both data and publications, or through efforts to address educational needs. In an attempt to find suitable indicators [26], an expert group identified two further substantive items that they propose are needed for full characterisation of RRI, namely, sustainability and social justice/inclusion.

In summary, when structured according to the three Ps of R\&I: the purpose, process and product, the components of RRI can be characterised as follows.

It is important to note that the categories and components listed in Table 1 do not constitute an evaluation of the relative merits or importance of these factors. Rather, the table is intended as an overview of RRI constituents and illustrates the multifactorial nature of RRI. We concede that there may be debate about certain factors, how they have been interpreted and how they have categorised here. For example, our decision to divide 'ethics' into research ethics (process) and broader ethical reflection (purpose) could, in itself, lead to complex debate about the what, why and how we attend to the ethical implications of R\&I. Similarly, our decision to categorise some of the EC pillars of RRI as 'product' and some as 'process' may not meet with full agreement. However, for the line of reasoning that is taken in this paper, the detailed allocation of individual components is less important than the recognition that these categories and components are indeed representative of most notable constituents of RRI.

Having now provided an overview of our understanding of RRI, we move on to describe how we came to develop the RRI maturity model. 
Table 1. Categories and components of RRI.

\begin{tabular}{cc}
\hline RRI Category & RRI Component \\
\hline Purpose (motivation) & Motivation for doing the research \\
& Motivation for engaging with RRI \\
Ethics (justification of intended outcomes) & Anticipation \\
Engagement & Reflection \\
Process (activities undertaken) & Governance \\
& Ethics (research ethics) \\
Responsiveness \\
\hline Product (outcomes) & Gender/equality and diversity \\
& Open access \\
& Social justice/inclusion \\
Sustainability \\
Science education
\end{tabular}

\section{Towards an RRI Maturity Model}

So far we have highlighted that RRI can be beneficial to organisations, and that there is a discrete set of categories and components that represent RRI in a comprehensive manner. In this section, we draw upon these insights, as well as the view of RRI as meta-responsibility, in our construction of the RRI maturity model. However, we begin with an introduction to the concept of maturity models.

\subsection{Maturity Models}

The idea of a maturity model is not new. The first and probably most widely cited maturity model is the capability maturity model for software [27]. This model aimed to demonstrate the value of software development for projects and organisations by defining a set of discrete stages of maturity development that software can inhabit. It proved to be a valuable tool that helps organisations to reflect upon their status at any given point in time and to identify appropriate future developments. The principle of expressing the current state of affairs in a particular domain through a model that contains possible stages of maturity is not limited to software development; it is also relevant to other areas of organisational development and reflection. For example, this method can be used for the identification of likely upcoming developments for particular technologies or for their integration into social systems. Maturity models have therefore been proposed for a range of application areas including e-government [28], supply chain management [29], business process management [30] or IT outsourcing [31]. It is worth noting that maturity models are not confined to this type of technology and management-related activities but have also been applied to other areas which are potentially closer to RRI, such as corporate social responsibility [32] and stakeholder relationship management [33].

There are different ways in which maturity models can be developed. On one hand, the top-down approach [34] predefines a set of stages of maturity which are then linked to certain aspects that can be assessed to indicate the stage of an organisation. On the other hand, the bottom-up construction of a maturity model is based upon insights emerging from detailed research about the organisation or field.

In practice, the development of such models tends to sit somewhere on a continuum between these two extremes of complete bottom-up or full-scale top-down approach. This is also true for the RRI maturity model developed here. The model was informed by a significant amount of research investigating the value and relevance of RRI in industry but was ultimately formulated in a top-down manner. The research informing the model development was undertaken in the context of the project that we introduce in the following section. 
The Responsible-Industry Project

The Responsible-Industry project (www.responsible-industry.eu) is an EU-funded project that has explored how private corporations can conduct their R\&I activities responsibly. For methodological reasons, we focused on the technical field of information and communication technology (ICT) and its application to the grand challenge of health, demographic change and wellbeing. The project included a range of significant activities, both literature-based and empirical, that have contributed to our understanding of RRI for companies. Firstly, an extensive literature review to evaluate and synthesise current discourse surrounding RRI in the industrial context was undertaken, and this informed 30 in-depth interviews with industry thought leaders. These were complemented by five bottom-up case studies where companies and other stakeholders described their experiences of R\&I and evaluated potential links with RRI. Findings from the interviews and case studies informed an international Delphi Study on the topic of RRI in industry with more than 150 stakeholder participants, as well as international stakeholder dialogue through multi-stakeholder workshops. All of these activities supported the development of a Framework for RRI in industry [35].

This framework includes discussion of the main motivations for industry to engage with RRI; guidance on how to implement RRI and implications for policy. To test the framework, we undertook 15 industry-based focus groups, continued stakeholder dialogue with industry, CSOs and policymakers and, most importantly, we completed four in-depth case studies with companies to investigate the value of the framework in a detailed and practical manner.

Most of these activities are described elsewhere, several form the basis of papers in this special issue (see, for example, [13]) and all of them are captured and described in the relevant deliverables on the project website (www.responsible-industry.eu). Hence, we do not describe the findings from these activities in more detail here. However, it is important to understand that all of these activities directly or indirectly informed our view of RRI in industry and shaped the subsequent RRI maturity model.

With this background of the work undertaken around RRI in industry, we are now in a position to develop the RRI maturity model itself.

\subsection{The RRI Maturity Model}

Most maturity models consist of a combination of two aspects: the actual stages or levels of maturity as well as the activities, processes or artefacts that are associated with each level. For the latter, in the RRI maturity model, we drew upon our aforementioned categories of RRI, which lend themselves to assessment in terms of their maturity. These are the purpose, processes and products of R\&I and their constitutive components. For the stages or levels of maturity we adapted, tried and tested examples from other maturity models as described below.

\section{Levels of RRI Maturity}

The levels of maturity in any maturity model need to be relevant to that given situation and are thus decided upon by those who develop the model. Additionally, the development of maturity does not conform to a particular number of stages; there is no set number of levels. Boundaries between levels tend to be continuous rather than discrete. One key quality of good maturity models is the selection of intuitively clear and convincing levels. Once established, it is vital that these levels are shown to be empirically relevant.

Following consultation with industry representatives, we decided upon use of the widespread approach of five levels of maturity for the RRI model. The characteristics of these levels are outlined in Figure 1: Stages of the RRI Maturity Model. 


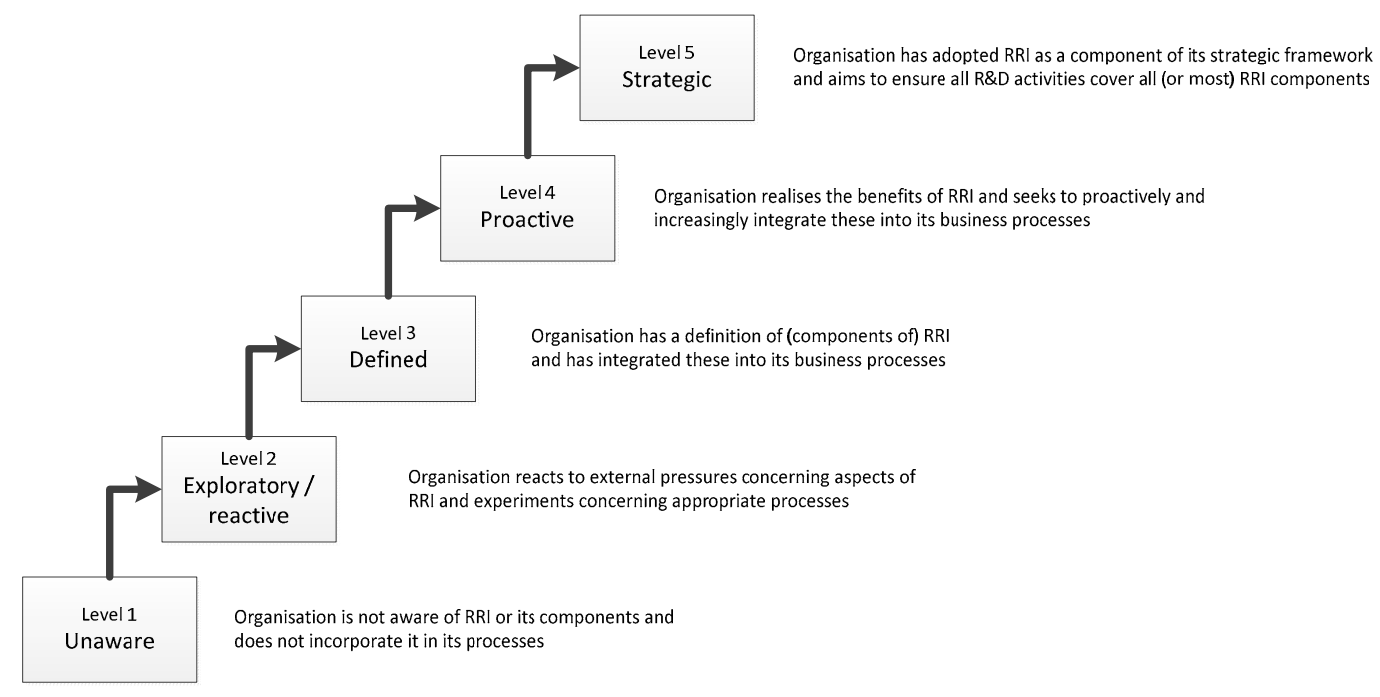

Figure 1. Stages of the RRI Maturity Model.

When combining these levels of RRI maturity with the categories and components of RRI, we arrive at a way of representing the RRI maturity model in the form of an overview table as shown in Table 2. This table offers a straightforward means of representing an organisation's RRI maturity level. Through identification of the appropriate level for each component of RRI, a company is able to clearly assess their own level of RRI maturity in terms of purpose, process and products of R\&I. It also reveals any areas that are lagging behind in development and thus inform future developments that are needed for greater RRI alignment.

Table 2. RRI Maturity Model Overview Table; Template for Organisational analysis.

\begin{tabular}{|c|c|c|c|c|c|}
\hline & & Unaware Exploratory/Reactive & Defined & Proactive & Strategic \\
\hline $\begin{array}{l}\text { Motivation } \\
\text { (purpose) }\end{array}$ & $\begin{array}{l}\text { Motivation for doing the research } \\
\text { Motivation for engaging with RRI } \\
\text { Ethics (intended outcomes) }\end{array}$ & & & & \\
\hline Process & $\begin{array}{c}\text { Anticipation } \\
\text { Engagement } \\
\text { Reflection } \\
\text { Governance } \\
\text { Ethics (research ethics) } \\
\text { Responsiveness }\end{array}$ & & & & \\
\hline $\begin{array}{l}\text { Outcomes } \\
\text { (product) }\end{array}$ & $\begin{array}{c}\text { Gender/equality and diversity } \\
\text { Open access } \\
\text { Social justice/inclusion } \\
\text { Sustainability } \\
\text { Science education }\end{array}$ & & & & \\
\hline
\end{tabular}

We would like to underline that the differences between levels are not as clear-cut as the representation above may suggest. As we will show in the validation of the model in the next section, the determination of the exact stage is at present only achievable via a qualitative judgment.

\subsection{Validation of the Model}

The model described in the previous sections is built on the discourse surrounding RRI on the one hand and maturity models on the other hand. It should have demonstrated that the idea of developing an RRI maturity model is feasible and can provide insights that organisations can use to reflect upon and improve their business processes. What it has not yet done is demonstrate its empirical validity. 
We therefore used three of the case studies alluded to earlier to check whether it was practically useful in describing and reflecting on the cases.

Case Study Methodology

Our approach to understanding organizational practices pertaining to RRI was motivated by the fact that much prior research on RRI is conceptual and empirical insights are required $[26,36]$. Moreover, existing studies are focused mainly on policy level research and its implications. More application-oriented innovation activities in companies are rarely included. Hence, our research investigated this phenomenon in a real-life cases [37].

Given cultural and developmental differences of ICT industry across countries, three respondent companies from three different countries (Finland, Spain, and Denmark) were selected to investigate the RRI in companies. Selecting companies from different countries also gave an opportunity to ask whether the maturity of the model differs across countries [38].

In order to identify "unique cases" [37], specific case selection criteria were developed. The company selection was focused on ICT companies that were developing ICT healthcare technologies, which we took to include technologies for rehabilitation, technologies for physical prevention, and assistive technologies. Two companies involved in the case study were small- and medium-sized enterprises (SME) and another case was a large company. The cases have been labelled 1 to 3 to ensure anonymity.

The full case study protocol including relevant research questions is available in [39]. Following this pre-defined case study protocol, we interviewed three different groups for each case:

1. High-level managers: Chief executive officer (CEO), Chief technology officer (CTO), Chief operating officer (COO).

2. Middle-level managers: Technological, innovation managers, and software development managers.

3. Technical staff: developers and technical support.

All interviewees were involved in two rounds of interviews. They also took part in the implementation phase, which was held between interview rounds. We used semi-structured interviews to ask interviewees about the implementation of RRI in their company. In addition, we ran a workshop between the two rounds of interviews, where we had an open discussion with interviewees to identify performance indicators for implementation of RRI. Triangulation of data was achieved by involving different researchers at various levels. All data collected from interviews and workshops were analyzed using qualitative data analysis software (NVivo) to assess the implementation of RRI in companies.

This document does not offer the space to describe the data collection, analysis and conclusion in much detail. Readers who are interested in the detail of the cases are referred to the relevant project deliverables A full comparative case analysis that would be sensitive to the differences between the three organizations and that could account for the institutional contexts and operational differences would go beyond the confines of this paper. Fortunately, such a detailed analysis of the cases is not required for the purposes of the present paper, which simply argues in favour of the development of an RRI maturity model and uses the cases as empirical evidence that this proposal is feasible and relevant.

In this paper, we use the cases to provide a set of empirical insights to allow us to judge the value of the RRI maturity model. For this purpose, the individual researchers in charge of the cases revised their data, in order to assess whether and to what degree the components of the RRI maturity model were visible in the companies. They then populated one instance of the RRI maturity model overview (Table 2) for each company, providing short explanations of why they ranked the particular component at the level they did. The researchers aimed to identify the maturity level, and their comments indicate why they believe that a particular level was achieved. In order to give the reader some more background, each of these cases is preceded by a short narrative of the company and the work they undertake as well as some details of the case research undertaken in each case. 
Case 1

The company that served as the basis of case study 1 is a welfare technology company (see Table 3 for a summary). It is based in Scandinavia but operates internationally. It is an SME with 17 employees. The company was founded in 2001 and develops interactive solutions for elderly people to help them stay at home longer and become more self-reliant in their everyday lives. One of their projects was the development of a software application for home care. This application could be used by elderly people themselves as well as by care staff. The user can order food or medication through the app and control things around the house; care staff is informed through a management system, relatives can get information, too. This shows the importance of engaging all relevant stakeholders in order to come to appropriate solutions. Research on the case comprised five initial interviews with the chief executive officer (CEO), the chief technology officer (CTO), a project manager, an interactive designer, and a digital designer that were held in January 2015. A set of five final interviews was conducted in March 2017.

Case 2

The second case study analysed the RRI maturity of a Finnish healthcare service company at a stage of intense growth (see Table 4 for a summary). The company has developed a unique solution, an automatic medicine dispenser, which is placed in the client's home. It is a personal and reliable aid for those in need of long-term medication, as it eliminates the concerns caused by managing complex medical treatment. The company's automatic medicine dispensing service manages the dispensing of medicine to treat chronic conditions comprehensively and completely automatically. Treatment compliance of those with chronic conditions improves, and wellbeing and quality of life increase when medication is taken regularly. In this way, the person with a need for long-term medication can live at home longer, managing his or her own care independently.

The service is suitable for persons who are compliant with treatment, i.e., are motivated to manage their own medical treatment. Most of those in need of long-term medical treatment are motivated to take their medicine. Key advantages of the technology are:

- As the Finnish SME service is used to dispense medication, the caregiver can focus on direct care work and thus improve the interaction with the client.

- The automatic medicine dispenser makes sure that the patient takes his or her medication at the right time and in the right doses and no doses are missed.

- Municipalities can achieve significant direct and indirect cost savings using the Finnish SME service, which makes the caregivers' work more efficient and reduces the need for institutional care.

The company has around 50 employees. It was founded in 2008 and developed the concept and the product ever since. In 2017, the company's product won the health innovation of the year award in Finland.

In the context of the Responsible-Industry project, six persons in various positions (CEO, COO, managers, developers and sales) were interviewed in June 2016. A workshop on the implementation of RRI took place with the company in November 2016. The final interview with the five employees that had participated in all of the previous sessions took place in January 2017.

Case 3

This last case study analysed the RRI maturity of a large Spanish ICT company that has 3000+ employees and an annual turnover of more than $€ 200$ million (see Table 5 for a summary). The company was founded in 1973. Currently, its activity focuses on IT consultancy, infrastructure services, integration of information systems, outsourcing and the implantation of integrated solutions for business management. It has been participating in national and European research and development projects on ICT for ageing. It was the first Spanish ICT company to obtain the bequal 007/2015 certificate on social responsibility (with regard to disability). 
Table 3. Overview of RRI maturity in case 1.

\begin{tabular}{|c|c|c|c|c|c|c|}
\hline & & Unaware & Exploratory/Reactive & Defined & Proactive & Strategic \\
\hline \multirow{3}{*}{$\begin{array}{l}\text { Motivation } \\
\text { (purpose) }\end{array}$} & $\begin{array}{l}\text { Motivation for doing } \\
\text { the research }\end{array}$ & & $\begin{array}{l}\text { Company does research if } \\
\text { needed to meet their goal }\end{array}$ & & & \\
\hline & $\begin{array}{l}\text { Motivation for engaging } \\
\text { with RRI }\end{array}$ & No awareness of RRI & & & & \\
\hline & Ethics (intended outcomes) & & $\begin{array}{l}\text { Company reacts to } \\
\text { ethical guidelines }\end{array}$ & & & \\
\hline \multirow{6}{*}{ Process } & Anticipation & & $\begin{array}{l}\text { Horizon scanning for specific } \\
\text { product lines }\end{array}$ & & & \\
\hline & Engagement & & & & & $\begin{array}{l}\text { User testing is embedded in } \\
\text { R\&D; in addition, other } \\
\text { stakeholders are also engaged. }\end{array}$ \\
\hline & Reflection & $\begin{array}{l}\text { No explicit } \\
\text { procedures implemented }\end{array}$ & & & & \\
\hline & Governance & $\begin{array}{l}\text { No explicit attention to } \\
\text { R\&I governance }\end{array}$ & & & & \\
\hline & Ethics (research ethics) & & $\begin{array}{l}\text { Ethics review is applied } \\
\text { if needed }\end{array}$ & & & \\
\hline & Responsiveness & & $\begin{array}{l}\text { Following and applying } \\
\text { regulations and standards }\end{array}$ & & & \\
\hline \multirow{5}{*}{$\begin{array}{l}\text { Outcomes } \\
\text { (product) }\end{array}$} & $\begin{array}{l}\text { Gender/equality } \\
\text { and diversity }\end{array}$ & & & $\begin{array}{l}\text { Gender equality and } \\
\text { diversity integrated into } \\
\text { business processes }\end{array}$ & & \\
\hline & Open access & $\begin{array}{l}\text { No explicit attention to } \\
\text { open access }\end{array}$ & & & & \\
\hline & Social justice/inclusion & $\begin{array}{l}\text { Explicit attention to social } \\
\text { justice/inclusion }\end{array}$ & & & & \\
\hline & Sustainability & & $\begin{array}{l}\text { Sustainability action plans } \\
\text { applied if needed }\end{array}$ & & & \\
\hline & Science education & $\begin{array}{l}\text { No plan for } \\
\text { science education }\end{array}$ & & & & \\
\hline
\end{tabular}


Table 4. Overview of RRI maturity in case 2.

\begin{tabular}{|c|c|c|c|c|c|}
\hline & & Unaware & Exploratory/Reactive & Proactive & Strategic \\
\hline \multirow{3}{*}{$\begin{array}{c}\text { Motivation } \\
\text { (purpose) }\end{array}$} & Motivation for doing the research & & & The company aims to promote public good & $\begin{array}{l}\text { Quality of Life of end-users is } \\
\text { a key motivation of the company }\end{array}$ \\
\hline & Motivation for engaging with RRI & & & $\begin{array}{l}\text { The company believes that most of the components of } \\
\text { RRI are vital for their success }\end{array}$ & \\
\hline & Ethics (intended outcomes) & & & Tracks outcomes and seeks evidence for positive results & \\
\hline \multirow{6}{*}{ Process } & Anticipation & & & $\begin{array}{l}\text { The product has to work properly, so risk assessment is } \\
\text { a critical part of the process Anticipation and } \\
\text { consideration of issues beyond compliance }\end{array}$ & \\
\hline & Engagement & & & $\begin{array}{l}\text { Stakeholder engagement is vital part of the process in } \\
\text { order to provide a service to fit to the purpose } \\
\text { (effectiveness), make service efficient (save time of } \\
\text { home care employees) for more important task and } \\
\text { satisfaction (pleasurable user experience) }\end{array}$ & \\
\hline & Reflection & & & $\begin{array}{l}\text { Quality issues are followed and improved based on } \\
\text { feedback and voluntarily }\end{array}$ & \\
\hline & Governance & & & $\begin{array}{l}\text { Many of the RRI components are already regulated at } \\
\text { some level, but the company goes beyond the } \\
\text { compliance of laws and regulations }\end{array}$ & \\
\hline & Ethics (research ethics) & & Ethics review needed for user studies & & \\
\hline & Responsiveness & & & $\begin{array}{l}\text { Company has regulated and voluntary based actions } \\
\text { for issues of vigilance and user feedback }\end{array}$ & \\
\hline \multirow{5}{*}{$\begin{array}{l}\text { Outcomes } \\
\text { (product) }\end{array}$} & Gender/equality and diversity & & Regulated by law & & \\
\hline & Open access/open innovation & & $\begin{array}{l}\text { Company publishes studies, but does not } \\
\text { actively seek or support open access policy }\end{array}$ & & \\
\hline & Social justice/inclusion & & $\begin{array}{l}\text { Service is acquired by public organisations so } \\
\text { company does not have direct link to support } \\
\text { social justice }\end{array}$ & & \\
\hline & Sustainability & & & $\begin{array}{l}\text { Environmental sustainability is covered by law but also } \\
\text { by voluntary actions }\end{array}$ & \\
\hline & Science education/capacity building & & & $\begin{array}{l}\text { Training of organisations to use system is part of } \\
\text { service provision }\end{array}$ & \\
\hline
\end{tabular}


Table 5. Overview of RRI maturity in case 3.

\begin{tabular}{|c|c|c|c|c|c|c|}
\hline & & Unaware & Exploratory/Reactive & Defined & Proactive & Strategic \\
\hline \multirow{3}{*}{$\begin{array}{c}\text { Motivation } \\
\text { (purpose) }\end{array}$} & $\begin{array}{l}\text { Motivation for doing } \\
\text { the research }\end{array}$ & & $\begin{array}{l}\text { Curiousness about the } \\
\text { possibilities to implement RRI }\end{array}$ & & & \\
\hline & $\begin{array}{l}\text { Motivation for engaging } \\
\text { with RRI }\end{array}$ & No awareness of RRI & & & & \\
\hline & Ethics (intended outcomes) & & & $\begin{array}{l}\text { Ethical codex in place; specific } \\
\text { procedures for security } \\
\text { risk-related projects }\end{array}$ & & \\
\hline \multirow{6}{*}{ Process } & Anticipation & & & $\begin{array}{l}\text { Risk analysis of future effects of } \\
\text { their software }\end{array}$ & & \\
\hline & Engagement & & & User-centred design wherever possible & & \\
\hline & Reflection & $\begin{array}{l}\text { No explicit procedures } \\
\text { implemented }\end{array}$ & & & & \\
\hline & Governance & $\begin{array}{l}\text { No explicit attention to R\&I } \\
\text { governance }\end{array}$ & & & & \\
\hline & Ethics (research ethics) & & & & $\begin{array}{l}\text { Ethics analysis of ongoing } \\
\text { R\&I projects }\end{array}$ & \\
\hline & Responsiveness & & & $\begin{array}{l}\text { Following and applying regulations } \\
\text { and standards }\end{array}$ & & \\
\hline \multirow{5}{*}{$\begin{array}{l}\text { Outcomes } \\
\text { (product) }\end{array}$} & Gender/equality and diversity & & & & & $\begin{array}{l}\text { Means for gender equality and } \\
\text { diversity implemented }\end{array}$ \\
\hline & Open access & & $\begin{array}{l}\text { In public projects, otherwise } \\
\text { avoidance of conflicts with } \\
\text { intellectual property }\end{array}$ & & & \\
\hline & Social justice/inclusion & & & & $\begin{array}{l}\text { Projects and initiatives for } \\
\text { social inclusion }\end{array}$ & \\
\hline & Sustainability & & & & $\begin{array}{l}\text { Annual action plans for } \\
\text { sustainability + ISO } 14001\end{array}$ & \\
\hline & Science education & & & $\begin{array}{l}\text { Training of staff in necessary } \\
\text { technological skills programmes }\end{array}$ & & \\
\hline
\end{tabular}


In the context of the Responsible-Industry project, seven managers, developers and marketing staff members were interviewed in November 2015. A workshop on the implementation of RRI took place with three of these employees in May 2016. One manager participated in the project workshop in Berlin in June 2016. The final interview with the three staff members that had participated in all of the previous sessions took place in October 2016.

\subsection{Case Comparison}

The empirical cases described in the previous sections illustrate the value of the RRI maturity model. They show that the model is applicable and allows a differentiated understanding of the role of the various RRI components in the company. However, and possibly even more importantly, the RRI maturity model offers the possibility of comparing organisations against each other and, assuming a larger amount of data is available, the development of specific benchmarks.

Given the relatively large number of components of the RRI maturity model and the five levels each of those can achieve, it is important to find a way of representing the model that demonstrates these different components. The figure below shows a summary of the three cases using a radar diagram, representing each of the cases in a different color (see Figure 2).

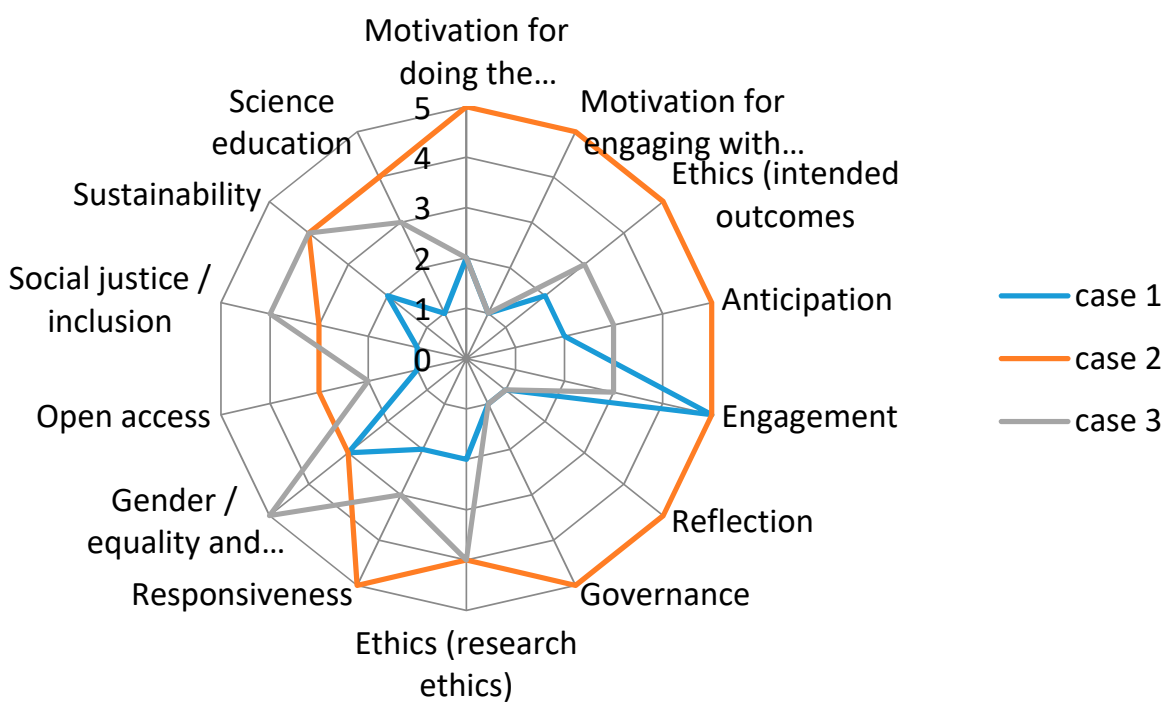

Figure 2. Representation of the RRI maturity of the three cases (maturity level represented by distance from the centre).

Using this type of figure, it is easy to gain a quick overview of the particular strengths and weaknesses of a given organisation. It is equally possible to compare these with competitor organisations or with organisations from different sectors. It provides a quick and high-level overview that is important to communicate the status of RRI in an organisation to senior management but also to individuals who are responsible for working on any of the RRI components.

For the three cases shown here, it is clear that case 2 is on the highest level of RRI maturity, whereas case 1 is on the lowest level with case 3 typically being located between the other two. This is not surprising, as case 1 was the pilot case study that was selected on the basis of availability, whereas cases 2 and 3 were full in-depth cases where one selection criterion was that the organisation in question displayed a noticeable interest in activities that are close to RRI.

The representation of the three cases using the radar diagram compresses large amount of information into a quick overview. A more detailed analysis of each of the components would be possible and is being undertaken elsewhere (see project deliverables, op cit.). It is nevertheless of interest to look at some issues in more detail. One noticeable aspect is the spike in the component of engagement. All three cases had high levels of engagement. This may be caused by their area of 
activity, i.e., ICT for health and ageing. This is a field where user engagement is prevalent and often required. It is therefore not surprising to see this spike of activities and it confirms the validity of the measure. Gender equality is another interesting component. Two of the companies had specific programmes in place to deal with gender equality, which can be seen as an indicator of the fact that gender equality is a well-established issue that many companies in the ICT sector are aware of and are trying to address actively.

A notable issue with our findings is in the area of motivation for engaging with RRI. All three of the cases scored poorly here, even though in some cases they did successfully pursue RRI in practice. The explanation for this apparent contradiction is that the score for the motivation component is derived from the fact that the term "RRI" was unknown to the respondents in the cases. However, many of the activities that constitute RRI were well familiar and could therefore score highly. This points to the problem of introducing novel concepts into a debate which typically take time to be adopted and integrated into organisation discourse.

One important insight to be gained from this comparison of the RRI maturity levels of the three cases is that there is no uniformity across the different components. All three cases display different levels of maturity in different areas, thus indicating that improvements are possible in different areas. The RRI maturity model can thus point out to organisations where they need to focus, in order to strengthen their performance, and there they show particular strengths or weaknesses when compared to their competitors.

A more detailed comparison of the cases is provided elsewhere. For the purposes of this paper, it suffices to state that the cases have provided insights that can be mapped to the RRI maturity model and show that this model is realistic and useful.

\section{Delivery of the RRI Maturity Model}

Having now demonstrated the conceptual relevance and empirical applicability of the RRI maturity model, the next question is how best to deliver it. One key question that we have not yet explored is how the levels of the different components can be measured and ascertained. In the empirical case examples given above, we provide a short indication of why the researcher in the particular cases set the attribution of a level to a component would be appropriate. This is consistent with the principles of interpretive research that recognise the important role of the researcher in interpreting findings [38-40].

However, this approach requires a significant investment of time into the research of each individual case to allow the researcher to gain the level of insight that is needed to determine the appropriate maturity level. This method does not scale up easily and is therefore problematic, if the RRI maturity model is supposed to be used more widely. It is therefore desirable to find a more widely applicable way of dealing with the question of determining adequate RRI maturity levels.

One way of achieving the aim of rendering the RRI maturity model more widely is to draw on the expertise of those who are involved in the projects and work in the organisations of interest. These individuals have the subject knowledge of motivation, processes and outcomes. However, they normally lack the knowledge of RRI required to assess the maturity levels of their work. These individuals require tools and support to help them categorise their practices in terms of RRI maturity.

One suitable way of providing this support and guiding individuals to a deeper understanding of RRI is to provide them with an RRI-specific self-assessment tool. This is a well-established method, for example, employed by the B-Corporation (http://bimpactassessment.net/bcorporation, accessed on 26 March 2017) or the Improve Academy for innovation management (https:/ / www.improveinnovation.eu/our-services/assessments/, accessed on 26 March 2017). Developing such a tool is therefore one natural next step arising from the RRI maturity model indicated above.

This paper does not offer the space to explore the details of such an RRI self-assessment tool. Developing the tool will raise a number of challenges, for example, with regards to the questions or items that should be employed to measure the RRI maturity level of the various components or the reliability 
and validity of the input variables. It is important to note, however, that this development would not have to start from zero. There are a number of outputs of prior research on RRI that have started to delineate the areas to be covered and that have gone some way towards a mature self-assessment tool. To name some prominent examples, one could point to the self-reflection tool provided by the RRI-Tools project (https: / / www.rri-tools.eu/self-reflection-tool, accessed on 5 May 2017), the Responsibility Navigator (http:/ / responsibility-navigator.eu/, accessed on 5 May 2017) or the Framework for RRI in ICT [18] (http:/ / www.orbit-rri.org/framework/, accessed on 5 May 2017). We therefore believe that the development of the tool should be a relatively straightforward task.

From our experience of working with companies, we conclude, however, that the provision of such a tool, while a necessary condition for the broader spread of awareness of RRI and its organisational relevance, will not suffice to influence organisational practices. For RRI to actually become practically relevant, there are at least two further conditions that need to be fulfilled. First, organisations need to understand the value of RRI and decide to adopt it. This question of why organisations would wish to adopt RRI is discussed elsewhere in this special issue, but it is important to see that it holds the key to successful diffusion of RRI. Second, an organisation that consciously adopts RRI and self-assesses its RRI maturity will still need more detailed guidance with regards to what it should do to improve its RRI maturity levels. There is an increasing amount of literature available that discusses this question, but on its own, this literature is not likely to make a difference. Organisations need practical support in implementing RRI through an infrastructure and network of experts and support agencies. These are slowly evolving, but it is not clear whether they are sufficient in spread and expertise to sustainably influence and support the further diffusion of RRI in organisations.

\section{Conclusions}

In this paper, we have developed a maturity model for RRI. We have argued that such a model would be useful for organisations to understand and reflect on their current practice and compare this with good practices in industry. Drawing on the current discourse of RRI, we identified categories and components of RRI that could serve as main building blocks of the model. Based on the literature on maturity models as well as our experience of working with companies, we defined a set of five maturity levels of RRI. Together, the components and maturity levels constitute the basis of the RRI maturity model.

Having thus developed the RRI maturity model, we used our empirical insights developed in a number of in-depth case studies to demonstrate the validity of the model and show how it can inform organisations with regards to strength and weaknesses of their current practice.

As indicated above, the literature on RRI has reached a significant level of maturity. While competing definitions of the concept continue to co-exist, there is much agreement on the main activities it contains. The two main competing interpretations of RRI are one the one hand, the version put forward by Stilgoe, Owen et al. $[7,41]$ and adopted by the UK EPSRC [8] and on the other hand, the European Commission's focus on the keys of RRI $[10,26]$. This paper demonstrates that these two interpretations can be unified into one view of RRI that will allow for a dynamic usage of the different components, which can be driven by specific needs and interests. This has both practical and theoretical importance.

The paper makes an important contribution to the practice of RRI in industry, by providing a relevant and applicable way of representing and reflecting upon the level to which RRI is realised. Such a practical way of approaching RRI is important, if the concept and the related practices are to be relevant beyond publicly funded research. At the same time, we believe that the paper makes a significant theoretical contribution to the current discourse on RRI by its combination of different interpretations of RRI. The RRI maturity model that we propose in this paper has the advantage of being adaptable and allowing for the seamless integration of the various components that influence the purpose, process and outcome of R\&I activities.

The theoretical contribution of the paper moves beyond its ability to combine existing prior conceptions of RRI. We believe that it provides an important argument in developing the concept 
of RRI as a meta-responsibility. As discussed earlier in this paper, we believe that RRI, if it is to be theoretically interesting and practically relevant, needs to be more than just an amalgamation of already existing practices and areas of interest. The concept of RRI as a meta-responsibility provides this additional angle on RRI, which allows it to combine existing activities and move beyond them. One crucial component required for RRI to be able to assume this position of a meta-responsibility is a bird's eye view of the R\&I-related processes, actors and responsibilities components. This high level overview of RRI and its implementation in a project or an organisation is required for the concept of a meta-responsibility to be accessible and interesting. The idea of a meta-responsibility implies that there are different levels of abstraction that can be used to assess or interpret RRI. Prior to this paper, however, there was no conceptual framework that would allow for such an interpretation of RRI. The RRI maturity model has the advantage of providing just such a conceptual framework. This is interesting because it lends itself to an analysis of current gaps and weaknesses of RRI in a particular project or organisation. This then provides the starting point to shape, maintain, develop, coordinate and align existing and novel processes to ensure that RRI has the intended socially acceptable, desirable and sustainable consequences. The RRI maturity model is a tool that generally over views and provides an empirically tested basis for drawing practical conclusions that can inform organisational practice. Its theoretical contribution to the discussion of RRI is thus twofold: It firstly allows for a more comprehensive view of RRI that combines existing accounts and it secondly allows moving beyond the one-dimensional view of RRI to a multi-dimensional account that paves the way for practical interventions.

We therefore believe that the RRI maturity model as introduced in this paper is likely to have a significant impact on the RRI discourse. If this idea is accepted, it also points in the direction of future work. The paper presented here is based on the work undertaken in a specific project which focused our understanding as well as the empirical research in a particular direction. Our work looked specifically at RRI in companies that work in the area of ICT for health, demographic change and well-being. Companies working in this area are typically guided by the nature of the technology they develop, which is often subject to specific regulation such as that pertaining to medical devices. At the same time, their intended end users tend to be people with health problems, which imprints a certain interpretation of social responsibility on their work. The RRI maturity model that we present here is kept as generic as possible, but we concede that it may require adaptation for other areas of industry. There are numerous questions that can be pursued from this starting point. The potential impact of RRI on ICT is high, but what about less customer-centred areas like business-to-business industries? What is the situation in industries with less or even no technological research and development activities? As the importance of considering sustainability issues in corporate innovation processes is acknowledged [42], further research is required to bring RRI into a broader context.

The next major challenge is related to the question of implementation of the model. We discussed the idea of implementing it through a self-assessment tool. Creating such a tool that would reliably measure the various components of RRI, reflect prior work and be usable and intuitively accessible will require significant efforts. We believe, however, that such a follow-up step is required in order to ensure that the RRI maturity model presented in this paper can acquire the practical relevance that we believe it deserves and that is required to allow RRI in industry to progress to the next step.

Acknowledgments: The research leading to these results received funding from the European Community's Seventh Framework Programme (FP7/2007-2013) under grant agreement $n^{\circ} 609817$ (Responsible-Industry). The authors would like to acknowledge the contribution of all project participants and all project activities to the ideas that underpin this paper.

Author Contributions: Bernd Carsten Stahl coordinated the project and drafted this paper; Michael Obach was responsible for case study 3; Alexander Brem and Emad Yaghmaei led the case study research and undertook case study 1; Veikko Ikonen was responsible for case study 2; Kate Chatfield led the interview study and qualitative data analysis.

Conflicts of Interest: The authors declare no conflict of interest. 


\section{References}

1. Von Schomberg, R. Towards Responsible Research and Innovation in the Information and Communication Technologies and Security Technologies Fields; Publications Office of the European Union: Luxembourg, 2011.

2. Nuffield Council on Bioethics. Novel Neurotechnologies: Intervening in the Brain: Short Guide; Nuffield Council on Bioethics: London, UK, 2013.

3. Von Schomberg, R. A Vision of Responsible Research and Innovation. In Responsible Innovation; Owen, R., Bessant, J., Heintz, M., Eds.; John Wiley \& Sons, Ltd.: Hoboken, NJ, USA, 2013; pp. 51-74. ISBN 978-1-118-55142-4.

4. Davis, M.; Laas, K. "Broader Impacts" or "Responsible Research and Innovation"? A Comparison of Two Criteria for Funding Research in Science and Engineering. Sci. Eng. Ethics 2013. [CrossRef]

5. Rip, A. The past and future of RRI. Life Sci. Soc. Policy 2014, 10, 17. [CrossRef] [PubMed]

6. Sutcliffe, H. A Report on Responsible Research and Innovation. 2011. Available online: https://ec. europa.eu/research/science-society/document_library/pdf_06/rri-report-hilary-sutcliffe_en.pdf (accessed on 14 June 2017).

7. Stilgoe, J.; Owen, R.; Macnaghten, P. Developing a framework for responsible innovation. Res. Policy 2013, 42, 1568-1580. [CrossRef]

8. Owen, R. The UK Engineering and Physical Sciences Research Council's Commitment to a Framework for Responsible Innovation. J. Responsib. Innov. 2014, 1, 113-117. [CrossRef]

9. European Commission. Responsible Research and Innovation-Europe's Ability to Respond to Societal Challenges; European Commission, Publications Office: Brussels, Belgium, 2012.

10. European Commission. Options for Strengthening Responsible Research and Innovation; Publications Office of the European Union: Luxembourg, 2013.

11. Grunwald, A. Responsible innovation: Bringing together technology assessment, applied ethics, and STS research. Enterp. Work Innov. Stud. 2011, 7, 9-31.

12. Stahl, B.C. Responsible research and innovation: The role of privacy in an emerging framework. Sci. Public Policy 2013, 40, 708-716. [CrossRef]

13. Chatfield, K.; Iatridis, K.; Stahl, B.C.; Paspallis, N. Innovating Responsibly in ICT for Ageing: Drivers, Obstacles and Implementation. Sustainability 2017, 9, 971. [CrossRef]

14. Blok, V.; Hoffmans, L.; Wubben, E.F.M. Stakeholder engagement for responsible innovation in the private sector: Critical issues and management practices. J. Chain Netw. Sci. 2015, 15, 147-164. [CrossRef]

15. Scholten, V.E.; Blok, V. Foreword: Responsible innovation in the private sector. J. Chain Netw. Sci. 2015, 15, 101-105. [CrossRef]

16. Iatridis, K.; Schroeder, D. Responsible Research and Innovation in Industry: The Case for Corporate Responsibility Tools; Springer: Heidelberg, Germany, 2015; ISBN 978-3-319-21693-5.

17. Brem, A.; Kreusel, N.; Neusser, C. Performance measurement in SMEs: Literature review and results from a German case study. Int. J. Glob. Small Bus. 2008, 2, 411-427. [CrossRef]

18. Jirotka, M.; Grimpe, B.; Stahl, B.; Hartswood, M.; Eden, G. Responsible Research and Innovation in the Digital Age. Commun. ACM 2017, 60, 62-68. [CrossRef]

19. Macnaghten, P.; Owen, R. Good governance for geoengineering. Nature 2011, 479, 293. [CrossRef] [PubMed]

20. Yusuf, M. Ethical issues in the use of the terminator seed technology. Afr. J. Biotechnol. 2010, 9, 8901-8904.

21. Oczek, J.P. In the Aftermath of the Terminator Technology Controversy: Intellectual Property Protections for Genetically Engineered Seeds and the Right to Save and Replant Seed Note. Boston Coll. Law Rev. 1999, 41, 627-658.

22. World Medical Association. Declaration of Helsinki-Ethical Principles for Medical Research Involving Human Subjects. 2008. Available online: https://www.wma.net/policies-post/wma-declaration-ofhelsinki-ethical-principles-for-medical-research-involving-human-subjects / (accessed on 14 June 2017).

23. European Commission. How to Complete Your Ethics Self-Assessment Version 5.2; European Commission-DG Research and Innovation: Brussels, Belgium, 2016.

24. Klitzman, R. The Ethics Police? The Struggle to Make Human Research Safe, 1st ed.; Oxford University Press (OUP): New York, NY, USA, 2015; ISBN 978-0-19-936460-2.

25. Schrag, Z.M. Ethical Imperialism: Institutional Review Boards and the Social Sciences, 1965-2009, 1st ed.; Johns Hopkins University Press: Baltimore, MD, USA, 2010; ISBN 978-0-8018-9490-9. 
26. Expert Group on Policy Indicators. Indicators for Promoting and Monitoring Responsible Research and Innovation. Available online: http://ec.europa.eu/research/swafs/pdf/pub_rri/rri_indicators_final_ version.pdf (accessed on 14 June 2017).

27. Paulk, M. Capability Maturity Model for Software. In Encyclopedia of Software Engineering; John Wiley \& Sons, Inc.: Hoboken, NJ, USA, 2002; ISBN 978-0-471-02895-6.

28. Andersen, K.V.; Henriksen, H.Z. E-government maturity models: Extension of the Layne and Lee model. Gov. Inf. Q. 2006, 23, 236-248. [CrossRef]

29. Lockamy, A.; McCormack, K. The development of a supply chain management process maturity model using the concepts of business process orientation. Supply Chain Manag. Int. J. 2004, 9, 272-278. [CrossRef]

30. De Bruin, T.; Rosemann, M. Towards a Business Process Management Maturity Model. In Faculty of Science and Technology; Bartmann, D., Rajola, F., Kallinikos, J., Avison, D., Winter, R., Ein-Dor, P., Becker, J., Bodendorf, F., Weinhardt, C., Eds.; Verlag and the London School of Economics: London, UK, 2005; pp. 1-12.

31. Gottschalk, P.; Solli-Sæther, H. Maturity model for IT outsourcing relationships. Ind. Manag. Data Syst. 2006, 106, 200-212. [CrossRef]

32. Calabrese, A.; Costa, R.; Menichini, T.; Rosati, F.; Sanfelice, G. Turning Corporate Social Responsibility-driven Opportunities in Competitive Advantages: A Two-dimensional Model. Knowl. Process. Manag. 2013, 20, 50-58. [CrossRef]

33. Bourne, L. Stakeholder Relationship Management: A Maturity Model for Organisational Implementation; CRC Press: Boca Raton, FL, USA, 2016; ISBN 978-1-317-05062-9.

34. Becker, J.; Knackstedt, R.; Pöppelbuß, J. Developing Maturity Models for IT Management. Bus. Inf. Syst. Eng. 2009, 1, 213-222. [CrossRef]

35. Borsella, E.; Porcari, A.; Mantovani, E. Delphi Exercise Report and 1st Draft Implementation Plan. Responsible-Industry Project. 2015. Available online: http:/ /www.responsible-industry.eu/dissemination/ deliverables/D2.2-DelphiExerciseReportDraftImplementationPlan.pdf?attredirects=0\&d=1 (accessed on 14 June 2017).

36. Schroeder, D.; Ladikas, M. Towards principled Responsible Research and Innovation: Employing the Difference Principle in funding decisions. J. Responsib. Innov. 2015, 2, 169-183. [CrossRef]

37. Yin, R.K. Case Study Research: Design and Methods, 3rd ed.; Sage Publications, Inc.: Thousand Oaks, CA, USA, 2003; ISBN 0-7619-2553-8.

38. Rowley, J. Using case studies in research. Manag. Res. News 2002, 25, 16-27. [CrossRef]

39. Yaghmaei, E.; Brem, A. Case Study Protocol. Responsible-Industry, 2014. Available online: http://www. responsible-industry.eu/dissemination/deliverables /D3.1-CaseStudyProtocol.pdf?attredirects=0\&d=1 (accessed on 14 June 2017).

40. Butler, T. Towards a hermeneutic method for interpretive research in information systems. J. Inf. Technol. 1998, 13, 285-300. [CrossRef]

41. Stilgoe, J. Foreword: Why Responsible Innovation. In Responsible Innovation; Owen, R., Heintz, M., Bessant, J., Eds.; John Wiley \& Sons, Ltd.: Hoboken, NJ, USA, 2013.

42. Maier, M.; Brem, A.; Kauke, M. Exploring the boundaries of corporate social responsibility and innovation. Int. J. Innov. Sustain. Dev. 2016, 10, 312-337. [CrossRef]

(C) 2017 by the authors. Licensee MDPI, Basel, Switzerland. This article is an open access article distributed under the terms and conditions of the Creative Commons Attribution (CC BY) license (http://creativecommons.org/licenses/by/4.0/). 